\title{
Pembuatan Kata Kunci Otomatis Dalam Artikel Dengan Pemodelan Topik
}

\author{
Lucky Adhikrisna Wirasakti, Rony Permadi, Anggit Dwi Hartanto, Hartatik \\ Fakultas Ilmu Komputer, Program Studi Informatika, Universitas Amikom Yogyakarta,Yogyakarta, Indonesia \\ Email: ${ }^{1}$ lucky.30@students.amikom.ac.id, ${ }^{2}$ rony.permadi@students.amikom.ac.id, ${ }^{3}$ anggit@amikom.ac.id, \\ ${ }^{4}$ hartatik@amikom.ac.id \\ *) Email Penulis Korespondensi: rony.permadi@students.amikom.ac.id
}

\begin{abstract}
Abstrak-Penelitian ini bertujuan untuk mengetahui keyword yang cocok untuk digunakan dalam publikasi artikel pada sebuah blog, Model Latent Dirichlet Allocation (LDA), sebuah model probabilitas dimana akan menghasilkan beberapa macam topik yang berbeda. Diawali dengan mengambil data data dari artikel/ blog, kemudian dilakukan pemotongan artikel per bagian dan dilakukan preprocessing data, dan pengubahan vektor data menjadi corpus untuk dimodelkan dengan LDA, selanjutnya di lakukan clustering dengan K-Means untuk mencari topik dengan probabilitas tertinggi. Hasil penelitian menyebutkan dari Model LDA diperoleh 4 topik dengan 8 kata dengan nilai probabilitas paling tinggi yaitu, mesin (0.09375857), maksimal (0.064600445), mazda (0.10009629), varian (0.07572112), cx-8 (0.10170187), mazda (0.101048954), mobil (0.09820121), dan mazda (0.05679208).
\end{abstract}

Kata Kunci: Pemodelan Topik, Latent Dirichlet Allocation, K-Means, Artikel, Blogging

\begin{abstract}
This study aims to determine the appropriate keywords to be used in the publication of articles on the blog, the Latent Dirichlet Allocation (LDA) Model, an opportunity model which will produce a variety of different topics. Beginning with taking data from articles / blogs, then cutting articles per section and doing data preprocessing, and changing vector data into corpus to be modeled with LDA, then grouping with K-means to search for topics with higher assistance. The results of quoting from the LDA Model obtained 4 topics with 8 words with the highest probability value, mesin $(0.09375857)$, maksimal (0.064600445), mazda (0.10009629), varian (0.07572112), cx-8 (0.10170187), mazda (0.101048954), mobil (0.09820121), dan mazda (0.05679208)
\end{abstract}

Keywords: Topic Modeling, Latent Dirichlet Allocation, K-Means, Articles, Blogging

\section{PENDAHULUAN}

Di era sekarang sudah menjadi hal yang sangat lazim ketika seseorang akan berbagi sebuah informasi melalui media elektronik, berbagai macam platform dapat digunakan untuk saling bertukar informasi hingga pengetahuan, mulai yang paling dekat dengan manusia yaitu sosial media, hingga portal portal berita atau platform blogging. Sebuah artikel diharapkan untuk disimak oleh banyak pembaca dari berbagai asal, hal ini berkaitan erat dengan bagaimana cara penulis artikel memilih kata kunci (keyword) yang tepat untuk artikel tersebut, oleh karena itu penulis memberikan solusi untuk pemilihan kata kunci (keyword), pada dasarnya ini adalah masalah Topic Modelling, dimana artikel yang ditulis akan mencari dicari kata paling dominan dari bahasan artikel dan ditambah dengan perhitungan nilai probabilitas juga dapat ditentukan intensitas kata yang paling sering ditulis dalam artikel sehingga dapat digunakan sebagai keyword utama.Topic modelling dapat dibuat cluster sesuai dengan yang di tabelkan dengan akurasi yang cukup signifikan [1][7][8].

Hasil pengujian dokumen dengan LDA Topic modelling menghasilkan ketepatan sebesar $84.7 \%$ dan pengujian dengan sistem informasi multimedia menghasilkan ketepatan hingga 90\% keatas [2][3]. Penggunaan LDA Topic Modelling yang dikombinasikan dengan XGBoost berhasil bekerja secara signifikan lebih baik daripada di Support Vector Machine[4]. Latent Dirichlet (LDA) dengan metode Bayesian dengan estimasi parameter Gibbs Sampling, membuktikan bahwa hasil diperoleh dari data yang diterbitkan @kompascom dengan nilai probabilitas topik 0.10057.[5].

Penelitian ini berhasil membuktikan bahwa model topik belajar dari pesan gabungan oleh pengguna yang sama dapat menyebabkan kinerja yang unggul dalam masalah klasifikasi dan topik fitur model yang dapat meningkatkan kinerja secara umum.[6]. Dengan menggunakan topic modelling dan pengclusteran dengan algoritma k-means dapat diketahui bahwa kata yang memiliki probabilitas tertinggi terbukti memiliki kualitas untuk dapat digunakan sebagai kata kunci (keyword).

\section{METODE PENELITIAN}

\subsection{Data Collection}

Data yang digunakan berupa data berbentuk teks yang diperoleh dari artikel sebuah situs website atau blog. Pengumpulan data yang kami gunakan menggunakan metode scraping dan copy-paste. Dalam paper ini dicontohkan artikel "Mazda CX-8 Dirilis di Thailand, Mulai 746 Jutaan Rupiah! " yang memiliki sekitar 330 kata dan 2.163 karakter. 


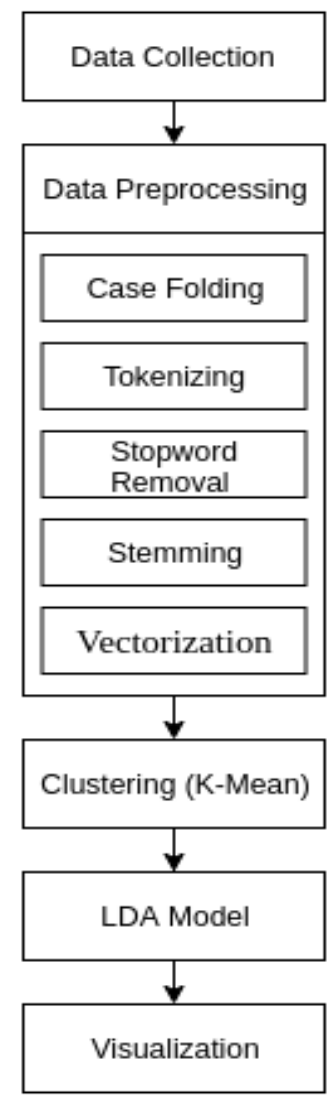

Gambar 1. Diagram Alir Tahapan Penelitian

\subsection{Data Preprocessing}

Pada tahapan ini kami melakukan pembersihan teks dari kata kata tidak diperlukan, mengubah setiap kata menjadi bentuk yang konsisten, pemotongan kalimat menjadi kata yang kemudian disebut sebagai token yang kemudian dilakukan penyaringan untuk mendapatkan kata penting serta menghilangkan kata tak bermakna, dan mengubah mengilangakan infleksi kata ke bentuk dasarnya. Tahap terakhir adalah mengubah bentuk kata menjadi representasi angka menggunakan bag-of-word vectorization.

Tabel 1. Data Preprocessing

\begin{tabular}{|l|l|}
\hline Original & $\begin{array}{l}\text { Setelah beberapa kali kami kabarkan, akhirnya Mazda CX-8 telah resmi diperkenalkan, di } \\
\text { Thailand. }\end{array}$ \\
\hline Case Folding & $\begin{array}{l}\text { setelah beberapa kali kami kabarkan akhirnya mazda cx telah resmi diperkenalkan di } \\
\text { thailand }\end{array}$ \\
\hline Tokenizing & $\begin{array}{l}\text { ['setelah', 'beberapa', 'kali', 'kami', 'kabarkan', 'akhirnya', 'mazda', 'cx', 'telah', 'resmi', } \\
\text { 'diperkenalkan', 'di', 'thailand'] }\end{array}$ \\
\hline Stopword Removal & {$[$ 'kali', 'kabarkan', 'mazda', 'cx', 'resmi', 'diperkenalkan', 'thailand'] } \\
\hline Stemming & ['kali', 'kabar', 'mazda', 'cx', 'resmi', 'kenal', 'thailand'] \\
\hline Vectorization & {$[[(0,1),(1,1),(2,1),(3,1),(4,1)]]$} \\
\hline
\end{tabular}

\subsection{Pembentukan Model LDA}

Setelah tahap pre-processing data, data tersebut kemudian direpresentasikan menjadi matriks pasangan kata dokumen untuk dapat dilakukan pembentukan model Latent Dirichlet Allocation (LDA) yang dibantu algoritma KMeans. Setelah mendapatkan model LDA dari data training maka model tersebut digunakan untuk data testing. Beberapa section dari data tersebut kami bagi menjadi 4 topik, dari 4 topik tersebut kami memperoleh nilai probabilitas dari kata yang sering digunakan di dalam masing-masing topik.

Tabel 2. Nilai probabilitas dari setiap topik

\begin{tabular}{llll}
\hline \multicolumn{1}{c}{ topic number: 0 } & \multicolumn{1}{c}{ topic number: 1 } & \multicolumn{1}{c}{ topic number: 2} & \multicolumn{1}{c}{ topic number: 3} \\
\hline (u'cx-8', 0.10170187) & (u'mobil', 0.09820121) & (u'mazda', 0.10009629) & (u'mesin', 0.09375857) \\
(u'mazda', 0.101048954) & (u'mazda', 0.05679208) & (u'varian', 0.07572112) & (u'maksimal', \\
(u'versi', 0.07814139) & (u'tawar', 0.055328712) & (u'mesin', 0.06374003) & $0.064600445)$ \\
(u'tawar', 0.078076504) & (u'hadir', 0.05507924) & (u'cx-8', 0.06360613) & (u'mazda', 0.037223388) \\
\hline
\end{tabular}


JURNAL MEDIA INFORMATIKA BUDIDARMA

Volume 4, Nomor 1, Januari 2020, Page 27-31

ISSN 2614-5278 (media cetak), ISSN 2548-8368 (media online)

Available Online at https://ejurnal.stmik-budidarma.ac.id/index.php/mib

DOI $10.30865 /$ mib.v4i1.1707

\begin{tabular}{|c|c|c|}
\hline $\begin{array}{l}\text { (u'opsi', 0.054140825) } \\
\text { (u'awd', 0.054056413) } \\
\text { (u'format', 0.05405217) } \\
\text { (u'thailand', 0.030206867) } \\
\text { (u'diesel', 0.030164963) } \\
\text { (u'chair', 0.030100225) }\end{array}$ & $\begin{array}{ll}\text { (u'tarik', 0.055005718) } & \text { (u'tara', 0.051485304) } \\
\text { (u'negeri', 0.054918345) } & \text { (u'baht', 0.051484644) } \\
\text { (u'sebut', 0.054903585) } & \text { (u'juta', 0.05147797) } \\
\text { (u'tumpang', 0.054833185)(u'rupiah', 0.0514739) } \\
\text { (u'advanced', 0.05478037) } & \text { (u'banderol', } \\
\text { (u'warning', 0.054691207) } & \begin{array}{l}0.039391022) \\
\text { (u'tawar', 0.027426526) }\end{array}\end{array}$ & $\begin{array}{l}\text { (u'cx-8', 0.036652535) } \\
\text { (u'tawar', 0.036238898) } \\
\text { (u'varian', 0.036167786) } \\
\text { (u'bensin', 0.036105964) } \\
\text { (u'tumpang', } \\
\text { 0.036064968) } \\
\text { (u'skema', 0.036047343) } \\
\text { (u'nm', 0.036044512) }\end{array}$ \\
\hline
\end{tabular}

Sebaran topik di tiap data berbeda-beda sehingga perlu dilakukan estimasi berapa topik yang mewakili data tersebut. Kami menggunakan algoritma kmeans untuk melakukan cluster dari data tersebut menjadi 4 cluster dari masing-masing topik dengan nilai probabilitas yang paling tinggi.

Tabel 3. Cluster dengan algoritma k-means

\begin{tabular}{|cccc|}
\hline cluster 0 words & cluster 1 words & cluster 2 words & cluster 3 words \\
\hline mesin,maksimal & mazda,varian & cx-8,mazda & mobil,mazda \\
\hline
\end{tabular}

\section{HASIL DAN PEMBAHASAN}

Dari data pre-processing kemudian dibuat bentuk pemodelan topik dengan Latent Dirichlet Allocation (LDA), pada masing-masing topik yang sudah di hitung nilai probabilitasnya kemudian diinterpretasikan ke dalam bentuk diagram

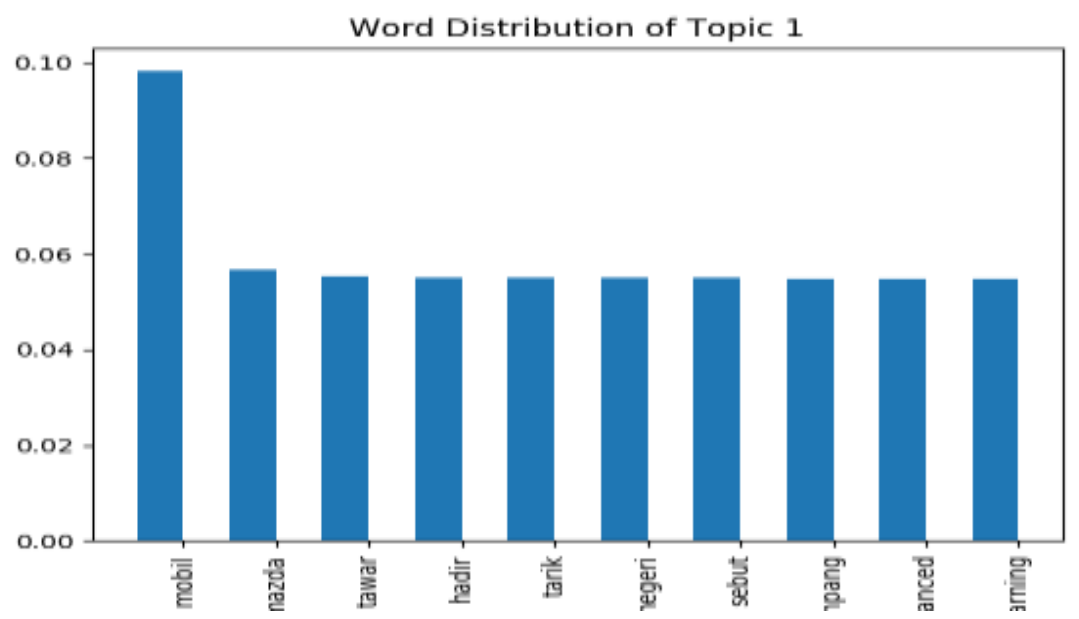

Gambar 2. Distribusi topik ke 1

Dari grafik pemodelan topik pertama dapat diketahui bahwa mobil menempati posisi pertama dan memiliki nilai probabilitas tertinggi yaitu dengan nilai 0.098, kemudian di posisi kedua ditempati oleh mazda dengan nilai 0.056. Dari grafik diatas keduanya dapat digunakan untuk mewakili topik pertama.

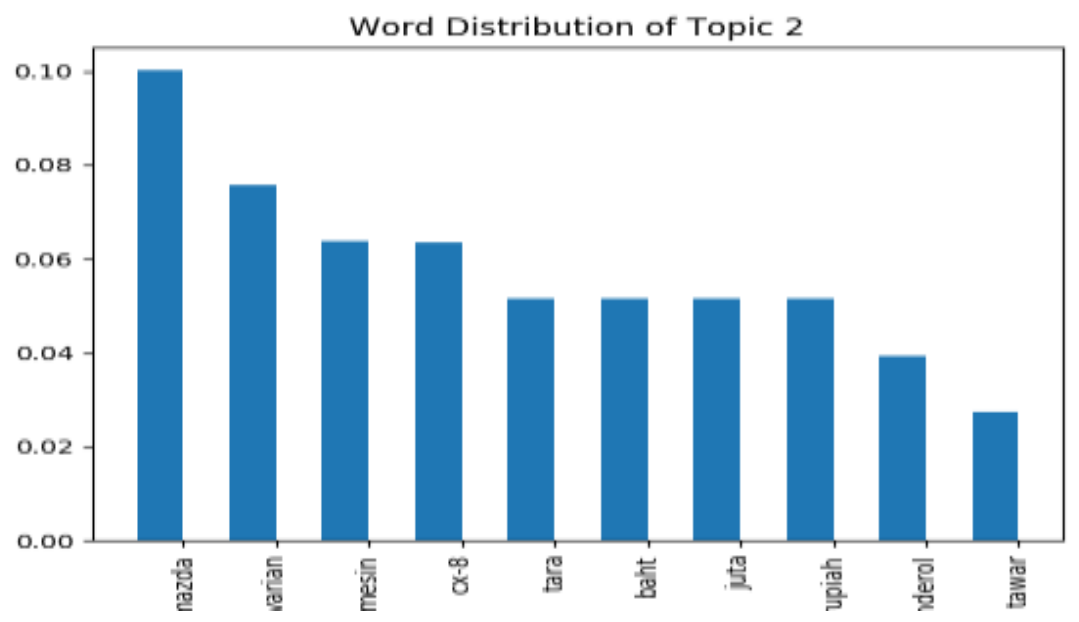

Gambar 3. Distribusi topik ke 2 
Dari grafik pemodelan topik kedua dapat diketahui bahwa mobil menempati posisi pertama dan memiliki nilai probabilitas tertinggi yaitu dengan nilai 0.098, kemudian diposisi kedua ditempati oleh mazda dengan nilai 0.056. Berbeda dengan grafik topik pertama, pada grafik topik kedua nilai probabilitas dari posisi pertama dan kedua jauh lebih tinggi daripada nilai probabilitas pada topik pertama. Pada grafik topik kedua ini mazda dan varian dapat digunakan untuk mewakili topik kedua.

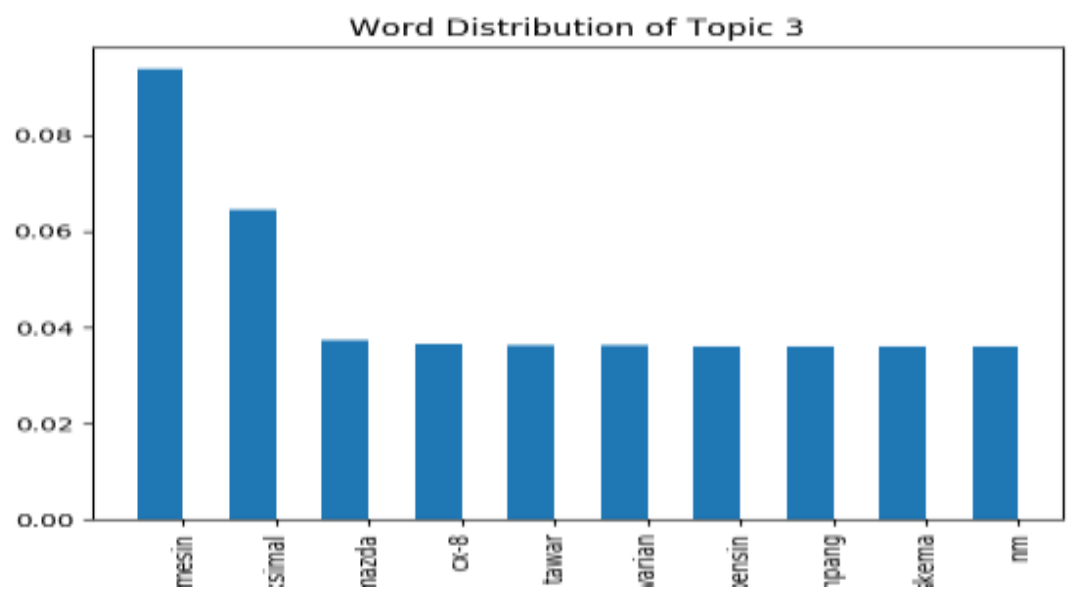

Gambar 4. Distribusi topik ke 3

Pada grafik pemodelan topik ketiga dapat diketahui bahwa mesin menempati posisi pertama dan memiliki nilai probabilitas tertinggi yaitu dengan nilai 0.093 , kemudian di posisi kedua ditempati oleh maksimal dengan nilai 0.064. Berbeda dengan kedua grafik topik sebelumnya, pada grafik topik kedua nilai probabilitas dari posisi pertama lebih rendah dari nilai probabilitas kedua topik lainnya dan pada posisi kedua nilai probabilitasnya lebih tinggi dari topik pertama tetapi lebih rendah dari topik kedua. Pada grafik topik ketiga ini mesin dan maksimal dapat digunakan untuk mewakili topik ketiga.

Dari keempat pemodelan topik, kami melakukan cluster pada masing-masing pemodelan topik dengan nilai probabilitas tertinggi untuk menentukan topik apa saja yang akan direkomendasikan dalam pembuatan kata kunci. Dari hasil clustering menunjukkan 4 topik dengan 8 kata dengan nilai probabilitas paling tinggi yang dapat digunakan sebagai kata kunci pada artikel yaitu, mesin, maksimal, mazda, varian, cx-8, mazda, mobil, dan mazda.

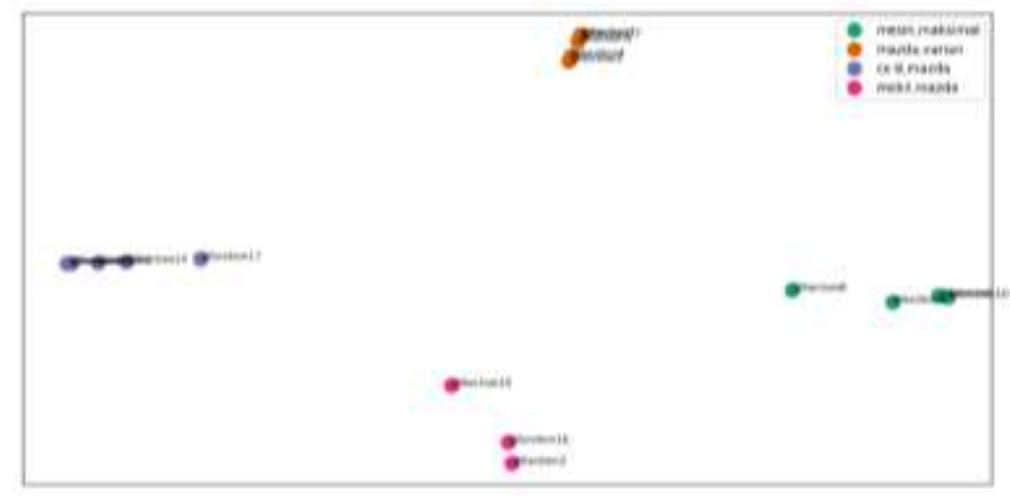

Gambar 5. Plot persebaran hasil clustering

\section{KESIMPULAN}

Berdasarkan hasil penelitian yang telah dilakukan dapat disimpulkan :

1. Data yang digunakan dalam penelitian berbentuk teks yang diperoleh dari artikel sebuah website atau blog.

2. Data kemudian dilakukan preprocessing dan dibagi menjadi beberapa section sesuai banyaknya teks yang terdapat dalam artikel.

3. Data yang sudah melalui tahap pre-processing kemudian direpresentasikan menjadi 4 topik sekaligus mencari nilai probabilitas pada setiap topik

4. Data tersebut dibuat bentuk pemodelan topik dan diinterpretasikan ke dalam gambar grafik yang berisi nilai probabilitas dari setiap topik.

5. Dari 4 topik tersebut dilakukan clustering menggunakan algoritma k-means untuk mengetahui topik mana yang mempunyai nilai probabilitas terbesar. 


\section{JURNAL MEDIA INFORMATIKA BUDIDARMA}

Volume 4, Nomor 1, Januari 2020, Page 27-31

ISSN 2614-5278 (media cetak), ISSN 2548-8368 (media online)

Available Online at https://ejurnal.stmik-budidarma.ac.id/index.php/mib DOI $10.30865 /$ mib.v4i1.1707

6. Hasil clustering dari pemodelan topik pada data tersebut dapat digunakan sebagai kata kunci artikel atau sebagai rekomendasi dalam membuat kata kunci.

Dari data artikel dengan judul "Mazda CX-8 Dirilis di Thailand, Mulai 746 Jutaan Rupiah! “ kami memperoleh hasil bahwa kata mesin, maksimal, varian, cx-8, mobil, dan mazda memiliki nilai probabilitas yang tinggi dan dapat digunakan sebagai rekomendasi dalam pembuatan kata kunci.

\section{REFERENCES}

[1] Y. P. N. S. Chyi-Kwei, "Clustering scientific documents with topic modeling," Springer Link, vol. 100, no. 3, p. 767786, September 2014.

[2] A. Agustina, "Analisis Dan Visualisasi Suara Pelanggan Pada Pusat Layanan Pelanggan Dengan Pemodelan Topik Menggunakan Latent Dirichlet Allocation (LDA)," ITS, Surabaya, 2017.

[3] I. G. A. d. H. Rosyid, "Penerapan Information Retrieval Menggunakan Pemodelan Topik Pada," in Jurnal Nasional Komputasi dan Teknologi Informasi (JNKTI), Banda Aceh, 2019.

[4] A. D. S. R. W. ,. D. S. A. E. N. E. W. A. M. N. S. "Veronica Ong, "Personality Prediction Based on Twitter Information," in Computer Science and Information Systems (FedCSIS), Prague, Czech Republic, 2017.

[5] Muh. Fajriyanto, "Penerapan Metode Bayesian Dalam Model Latent Dirichlet Allocation Di Media Sosial," 2018. [Online]. Available: http://journal.student.uny.ac.id/ojs/index.php/math/article/view/11158/10697. [Accessed November 2019].

[6] B. D. D. Liangjie Hong, "Empirical Study of Topic Modeling in Twitter," in First Workshop on Social Media Analytics, New York, NY, USA, 2010.

[7] S. $\quad$ B. $\quad$ T. I. G. N. M. J. Zulhanif, "LOGIK@," 2017. [Online]. Available: http://journal.uinjkt.ac.id/index.php/logika/article/view/6474/3963.

[8] E. R. J. C. C. D. M. a. D. A. M. Daniel Ramage, "Stanford University," 2009. [Online]. Available: http://nlp.stanford.edu/dramage/papers/tmt-nips09.pdf. 